\title{
Hyers-Ulam-Rassias stability of the additive-quadratic mappings in non-Archimedean Banach spaces
}

C Park ${ }^{1}, \mathrm{H}$ Azadi Kenary ${ }^{2 *}$ and TM Rassias ${ }^{3}$

\section{"Correspondence:}

azadi@mail.yu.ac.ir

${ }^{2}$ Department of Mathematics,

College of Sciences, Yasouj

University, Yasouj, 75914-353, Iran

Full list of author information is

available at the end of the article

\begin{abstract}
Using the fixed point and direct methods, we prove the generalized Hyers-Ulam normed spaces

$$
\begin{aligned}
& r\left[f\left(\frac{x+y+z}{s}\right)+f\left(\frac{x-y+z}{s}\right)+f\left(\frac{x+y-z}{s}\right)+f\left(\frac{-x+y+z}{s}\right)\right] \\
& \quad=\gamma f(x)+\gamma f(y)+\gamma f(z),
\end{aligned}
$$
\end{abstract}
stability of the following additive-quadratic functional equation in non-Archimedean

where $r, s, \gamma$ are positive real numbers.

MSC: Primary 39B55; 46S10

Keywords: Hyers-Ulam stability; fixed point method; non-Archimedean normed spaces

\section{Introduction and preliminaries}

A classical question in the theory of functional equations is the following: 'When is it true that a function which approximately satisfies a functional equation must be close to an exact solution of the equation?' If the problem accepts a solution, we say that the equation is stable. The first stability problem concerning group homomorphisms was raised by Ulam [44] in 1940. In the next year, Hyers [23] gave a positive answer to the above question for additive groups under the assumption that the groups are Banach spaces. In 1978, Rassias [39] proved a generalization of Hyers' theorem for additive mappings. This new concept is known as generalized Hyers-Ulam stability or Hyers-Ulam-Rassias stability of functional equations. Furthermore, in 1994, a generalization of Rassias' theorem was obtained by Gǎvruta [21] by replacing the bound $\epsilon\left(\|x\|^{p}+\|y\|^{p}\right)$ by a general control function $\varphi(x, y)$.

In 1983, a generalized Hyers-Ulam stability problem for the quadratic functional equation was proved by Skof [43] for mappings $f: X \rightarrow Y$, where $X$ is a normed space and $Y$ is a Banach space. In 1984, Cholewa [11] noticed that the theorem of Skof is still true if the relevant domain $X$ is replaced by an Abelian group and, in 2002, Czerwik [13] proved the generalized Hyers-Ulam stability of the quadratic functional equation. The reader is referred to [1-42] and references therein for detailed information on stability of functional equations.

@ 2012 Park et al.; licensee Springer. This is an Open Access article distributed under the terms of the Creative Commons Attribution License (http://creativecommons.org/licenses/by/2.0), which permits unrestricted use, distribution, and reproduction in any medium, provided the original work is properly cited. 
In 1897, Hensel [22] has introduced a normed space which does not have the Archimedean property. It turned out that non-Archimedean spaces have many nice applications (see $[16,25-27,33])$.

Definition 1.1 By a non-Archimedean field, we mean a field $\mathbb{K}$ equipped with a function (valuation) $|\cdot|: \mathbb{K} \rightarrow[0, \infty)$ such that for all $r, s \in \mathbb{K}$, the following conditions hold:

(1) $|r|=0$ if and only if $r=0$;

(2) $|r s|=|r||s|$;

(3) $|r+s| \leq \max \{|r|,|s|\}$.

Definition 1.2 Let $X$ be a vector space over a scalar field $\mathbb{K}$ with a non-Archimedean nontrivial valuation $|\cdot|$. A function $\|\cdot\|: X \rightarrow R$ is a non-Archimedean norm (valuation) if it satisfies the following conditions:

(1) $\|x\|=0$ if and only if $x=0$;

(2) $\|r x\|=|r\|\mid x\|(r \in \mathbb{K}, x \in X)$;

(3) The strong triangle inequality (ultrametric); namely,

$$
\|x+y\| \leq \max \{\|x\|,\|y\|\}, \quad x, y \in X
$$

Then $(X,\|\cdot\|)$ is called a non-Archimedean space.

Due to the fact that

$$
\left\|x_{n}-x_{m}\right\| \leq \max \left\{\left\|x_{j+1}-x_{j}\right\|: m \leq j \leq n-1\right\} \quad(n>m) .
$$

Definition 1.3 A sequence $\left\{x_{n}\right\}$ is Cauchy if and only if $\left\{x_{n+1}-x_{n}\right\}$ converges to zero in a non-Archimedean space. By a complete non-Archimedean space we mean one in which every Cauchy sequence is convergent.

Definition 1.4 Let $X$ be a set. A function $d: X \times X \rightarrow[0, \infty]$ is called a generalized metric on $X$ if $d$ satisfies

(1) $d(x, y)=0$ if and only if $x=y$;

(2) $d(x, y)=d(y, x)$ for all $x, y \in X$;

(3) $d(x, z) \leq d(x, y)+d(y, z)$ for all $x, y, z \in X$.

We recall a fundamental result in fixed point theory.

Theorem $1.5([13,17])$ Let $(X, d)$ be a complete generalized metric space and let $J: X \rightarrow X$ be a strictly contractive mapping with Lipschitz constant $\alpha<1$. Then for each given element $x \in X$, either

$$
d\left(J^{n} x, J^{n+1} x\right)=\infty
$$

for all nonnegative integers $n$ or there exists a positive integer $n_{0}$ such that

(1) $d\left(J^{n} x, J^{n+1} x\right)<\infty, \forall n \geq n_{0}$;

(2) the sequence $\left\{J^{n} x\right\}$ converges to a fixed point $y^{*}$ of $J$;

(3) $y^{*}$ is the unique fixed point of $J$ in the set $Y=\left\{y \in X \mid d\left(J^{n_{0}} x, y\right)<\infty\right\}$;

(4) $d\left(y, y^{*}\right) \leq \frac{1}{1-\alpha} d(y, J y)$ for all $y \in Y$. 
In 1996, G. Isac and Th. M. Rassias [24] were the first to provide applications of stability theory of functional equations for the proof of new fixed-point theorems with applications. By using fixed-point methods, the stability problems of several functional equations have been extensively investigated by a number of authors (see [14, 15, 35, 36, 40]).

This paper is organized as follows: In Section 2, using the fixed-point method, we prove the Hyers-Ulam stability of the following additive-quadratic functional equation:

$$
\begin{aligned}
& r f\left(\frac{x+y+z}{s}\right)+r f\left(\frac{x-y+z}{s}\right)+r f\left(\frac{x+y-z}{s}\right)+r f\left(\frac{-x+y+z}{s}\right) \\
& \quad=\gamma f(x)+\gamma f(y)+\gamma f(z)
\end{aligned}
$$

where $x, y, z \in X$, in non-Archimedean normed space. In Section 3, using direct methods, we prove the Hyers-Ulam stability of the additive-quadratic functional equation (1.1) in non-Archimedean normed spaces.

It is easy to see that a mapping $f$ with $f(0)=0$ is a solution of equation (1.1) if and only if $f$ is of the form $f(x)=A(x)+Q(x)$ for all $x \in X$.

\section{Stability of functional equation (1.1): a fixed point method}

In this section, we deal with the stability problem for the additive-quadratic functional equation (1.1). In the rest of the present article, let $|2| \neq 1$.

Theorem 2.1 Let $X$ is a non-Archimedean normed space and that $Y$ be a complete nonArchimedean space. Let $\varphi: X^{3} \rightarrow[0, \infty)$ be a function such that there exists an $\alpha<1$ with

$$
\varphi(2 x, 2 y, 2 z) \leq|2| \alpha \varphi(x, y, z)
$$

for all $x, y, z \in X$. Let $f: X \rightarrow Y$ be an odd mapping satisfying

$$
\begin{aligned}
& \| r f\left(\frac{x+y+z}{s}\right)+r f\left(\frac{x-y+z}{s}\right)+r f\left(\frac{x+y-z}{s}\right) \\
& \quad+r f\left(\frac{-x+y+z}{s}\right)-\gamma f(x)-\gamma f(y)-\gamma f(z) \|_{Y} \leq \varphi(x, y, z)
\end{aligned}
$$

for all $x, y, z \in X$. Then there exists a unique additive mapping $A: X \rightarrow Y$ such that

$$
\|f(x)-A(x)\|_{Y} \leq \frac{\max \{\varphi(2 x, 0,0), \varphi(x, x, 0)\}}{|2 \gamma|(1-\alpha)}
$$

for all $x \in X$.

Proof Putting $y=z=0$ in (2.2) and replacing $x$ by $2 x$, we get

$$
\left\|r f\left(\frac{2 x}{s}\right)-\frac{\gamma}{2} f(2 x)\right\|_{Y} \leq \frac{1}{|2|} \varphi(2 x, 0,0)
$$

for all $x \in X$. Putting $y=x$ and $z=0$ in (2.2), we have

$$
\left\|r f\left(\frac{2 x}{s}\right)-\gamma f(x)\right\|_{Y} \leq \frac{1}{|2|} \varphi(x, x, 0)
$$


for all $x \in X$. By (2.4) and (2.5), we get

$$
\begin{aligned}
\left\|\frac{f(2 x)}{2}-f(x)\right\|_{Y} & =\frac{1}{|\gamma|}\left\|\frac{\gamma}{2} f(2 x) \pm r f\left(\frac{2 x}{s}\right)-\gamma f(x)\right\|_{Y} \\
& \leq \frac{1}{|\gamma|} \max \left\{\left\|r f\left(\frac{2 x}{s}\right)-\frac{\gamma}{2} f(2 x)\right\|_{Y},\left\|r f\left(\frac{2 x}{s}\right)-\gamma f(x)\right\|_{Y}\right\} \\
& \leq \frac{1}{|2 \gamma|} \max \{\varphi(2 x, 0,0), \varphi(x, x, 0)\} .
\end{aligned}
$$

Consider the set $S:=\{h: X \rightarrow Y\}$ and introduce the generalized metric on $S$ :

$$
d(g, h)=\inf \left\{\mu \in(0,+\infty):\|g(x)-h(x)\|_{Y} \leq \mu \max \{\varphi(2 x, 0,0), \varphi(x, x, 0)\}, \forall x \in X\right\},
$$

where, as usual, $\inf \phi=+\infty$. It is easy to show that $(S, d)$ is complete (see [30]). Now we consider the linear mapping $J: S \rightarrow S$ such that $g g(x):=\frac{1}{2} g(2 x)$ for all $x \in X$. Let $g, h \in S$ be given such that $d(g, h)=\varepsilon$. Then

$$
\|g(x)-h(x)\|_{Y} \leq \epsilon \max \{\varphi(2 x, 0,0), \varphi(x, x, 0)\}
$$

for all $x \in X$. Hence,

$$
\begin{aligned}
\|J g(x)-J h(x)\|_{Y} & =\left\|\frac{1}{2} g(2 x)-\frac{1}{2} h(2 x)\right\|_{Y} \\
& =\frac{\|g(2 x)-h(2 x)\|_{Y}}{|2|} \\
& \leq \frac{\epsilon}{|2|} \max \{\varphi(4 x, 0,0), \varphi(2 x, 2 x, 0)\} \\
& \leq \alpha \cdot \epsilon \max \{\varphi(2 x, 0,0), \varphi(x, x, 0)\}
\end{aligned}
$$

for all $x \in X$. So $d(g, h)=\varepsilon$ implies that $d(J g, J h) \leq \alpha \varepsilon$. This means that $d(J g, J h) \leq \alpha d(g, h)$ for all $g, h \in S$.

It follows from (2.6) that $d(f, J f) \leq \frac{1}{|2 \gamma|}$. By Theorem 1.5, there exists a mapping $A: X \rightarrow$ $Y$ satisfying the following:

(1) $A$ is a fixed point of $J$, i.e.,

$$
2 A(x)=A(2 x)
$$

for all $x \in X$. The mapping $A$ is a unique fixed point of $J$ in the set $M=\{g \in S: d(h, g)<\infty\}$. This implies that $A$ is a unique mapping satisfying (2.7) such that there exists a $\mu \in(0, \infty)$ satisfying $\|f(x)-A(x)\|_{Y} \leq \mu \max \{\varphi(2 x, 0,0), \varphi(x, x, 0)\}$ for all $x \in X$;

(2) $d\left(J^{n} f, A\right) \rightarrow 0$ as $n \rightarrow \infty$. This implies the equality

$$
\lim _{n \rightarrow \infty} \frac{f\left(2^{n} x\right)}{2^{n}}=A(x) \quad \text { for all } x \in X
$$

(3) $d(f, A) \leq \frac{1}{1-\alpha} d(f, J f)$, which implies the inequality $d(f, A) \leq \frac{1}{|2 \gamma|(1-\alpha)}$. This implies that the inequalities (2.3) holds. 
It follows from (2.1) and (2.2) that

$$
\begin{aligned}
\| r A & \left(\frac{x+y+z}{s}\right)+r A\left(\frac{x-y+z}{s}\right)+r A\left(\frac{x+y-z}{s}\right) \\
& +r A\left(\frac{-x+y+z}{s}\right)-\gamma A(x)-\gamma A(y)-\gamma A(z) \|_{Y} \\
= & \lim _{n \rightarrow \infty} \frac{1}{|2|^{n} \mid} \| r f\left(\frac{2^{n}(x+y+z)}{s}\right)+r f\left(\frac{2^{n}(x-y+z)}{s}\right)+r f\left(\frac{2^{n}(x+y-z)}{s}\right) \\
& +r f\left(\frac{2^{n}(-x+y+z)}{s}\right)-\gamma f\left(2^{n} x\right)-\gamma f\left(2^{n} y\right)-\gamma f\left(2^{n} z\right) \|_{Y} \\
\leq & \lim _{n \rightarrow \infty} \frac{1}{|2|^{n}} \varphi\left(2^{n} x, 2^{n} y, 2^{n} z\right) \\
\leq & \lim _{n \rightarrow \infty} \frac{1}{|2|^{n}} \cdot|2|^{n} \alpha^{n} \varphi(x, y, z) \\
= & 0
\end{aligned}
$$

for all $x, y, z \in X$. So

$$
\begin{aligned}
& r A\left(\frac{x+y+z}{s}\right)+r A\left(\frac{x-y+z}{s}\right)+r A\left(\frac{x+y-z}{s}\right) \\
& \quad+r A\left(\frac{-x+y+z}{s}\right)-\gamma A(x)-\gamma A(y)-\gamma A(z)=0
\end{aligned}
$$

for all $x, y, z \in X$. Hence, $A: X \rightarrow Y$ satisfying (1.1). This completes the proof.

Corollary 2.2 Let $\theta$ be a positive real number and $q$ is a real number with $q>1$. Let $f$ : $X \rightarrow Y$ be an odd mapping satisfying

$$
\begin{aligned}
& \| r f\left(\frac{x+y+z}{s}\right)+r f\left(\frac{x-y+z}{s}\right)+r f\left(\frac{x+y-z}{s}\right) \\
& \quad+r f\left(\frac{-x+y+z}{s}\right)-\gamma f(x)-\gamma f(y)-\gamma f(z) \|_{Y} \leq \theta\left(\|x\|^{q}+\|y\|^{q}+\|z\|^{q}\right)
\end{aligned}
$$

for all $x, y, z \in X$. Then there exists a unique additive mapping $A: X \rightarrow Y$ such that

$$
\|f(x)-A(x)\|_{Y} \leq \frac{2|2| \theta\|x\|^{q}}{|2 \gamma|\left(|2|-|2|^{q}\right)}
$$

for all $x \in X$.

Proof The proof follows from Theorem 2.1 by taking $\varphi(x, y, z)=\theta\left(\|x\|^{q}+\|y\|^{q}+\|z\|^{q}\right)$ for all $x, y, z \in X$. Then we can choose $\alpha=|2|^{q-1}$ and we get the desired result.

Theorem 2.3 Let $X$ is a non-Archimedean normed space and that $Y$ be a complete nonArchimedean space. Let $\varphi: X^{3} \rightarrow[0, \infty)$ be a function such that there exists an $\alpha<1$ with

$$
\varphi\left(\frac{x}{2}, \frac{y}{2}, \frac{z}{2}\right) \leq \frac{\alpha}{|2|} \varphi(x, y, z)
$$


for all $x, y, z \in X$. Let $f: X \rightarrow Y$ be an odd mapping satisfying (2.2). Then there exists a unique additive mapping $A: X \rightarrow Y$ such that

$$
\|f(x)-A(x)\|_{Y} \leq \frac{\alpha \max \{\varphi(2 x, 0,0), \varphi(x, x, 0)\}}{|2 \gamma|(1-\alpha)}
$$

for all $x \in X$.

Proof Let $(S, d)$ be the generalized metric space defined in the proof of Theorem 2.1.

Now we consider the linear mapping $J: S \rightarrow S$ such that

$$
J g(x):=2 g\left(\frac{x}{2}\right)
$$

for all $x \in X$.

Replacing $x$ by $\frac{x}{2}$ in (2.6) and using (2.9), we have

$$
\begin{aligned}
\left\|f(x)-2 f\left(\frac{x}{2}\right)\right\|_{Y} & \leq \frac{1}{|\gamma|} \max \left\{\varphi(x, 0,0), \varphi\left(\frac{x}{2}, \frac{x}{2}, 0\right)\right\} \\
& \leq \frac{\alpha}{|2 \gamma|} \max \{\varphi(2 x, 0,0), \varphi(x, x, 0)\} .
\end{aligned}
$$

So $d(f, J f) \leq \frac{\alpha}{|2 \gamma|}$.

The rest of the proof is similar to the proof of Theorem 2.1.

Corollary 2.4 Let $\theta$ be a positive real number and $q$ is a real number with $0<q<1$. Let $f: X \rightarrow Y$ be an odd mapping satisfying (2.8). Then there exists a unique additive mapping $A: X \rightarrow Y$ such that

$$
\|f(x)-A(x)\|_{Y} \leq \frac{2|2| \theta\|x\|^{q}}{|2 \gamma|\left(|2|^{q}-|2|\right)}
$$

for all $x \in X$.

Proof The proof follows from Theorem 2.3 by taking $\varphi(x, y, z)=\theta\left(\|x\|^{q}+\|y\|^{q}+\|z\|^{q}\right)$ for all $x, y, z \in X$. Then we can choose $\alpha=|2|^{1-q}$ and we get the desired result.

Theorem 2.5 Let $X$ is a non-Archimedean normed space and that $Y$ be a complete nonArchimedean space. Let $\varphi: X^{3} \rightarrow[0, \infty)$ be a function such that there exists an $\alpha<1$ with

$$
\varphi(2 x, 2 y, 2 z) \leq|4| \alpha \varphi(x, y, z)
$$

for all $x, y, z \in X$. Let $f: X \rightarrow Y$ be an even mapping with $f(0)=0$ and satisfying (2.2). Then there exists a unique quadratic mapping $Q: X \rightarrow Y$ such that

$$
\|f(x)-Q(x)\|_{Y} \leq \frac{\max \{\varphi(2 x, 0,0),|2| \varphi(x, x, 0)\}}{|4 \gamma|(1-\alpha)}
$$

for all $x \in X$. 
Proof Consider the set $S^{*}=\{g: X \rightarrow Y ; g(0)=0\}$ and the generalized metric $d^{*}$ in $S^{*}$ defined by

$$
d^{*}(g, h)=\inf \left\{\mu \in(0,+\infty):\|g(x)-h(x)\|_{Y} \leq \mu \max \{\varphi(2 x, 0,0),|2| \varphi(x, x, 0)\}, \forall x \in X\right\},
$$

where, as usual, $\inf \phi=+\infty$. It is easy to show that $\left(S^{*}, d^{*}\right)$ is complete (see [30]). Now we consider the linear mapping $J:\left(S^{*}, d^{*}\right) \rightarrow\left(S^{*}, d^{*}\right)$ such that

$$
J g(x):=\frac{1}{4} g(2 x)
$$

for all $x \in X$.

Putting $y=x$ and $z=0$ in (2.2), we have

$$
\left\|2 r f\left(\frac{2 x}{s}\right)-2 \gamma f(x)\right\|_{Y} \leq \varphi(x, x, 0)
$$

for all $x \in X$.

Substituting $y=z=0$ and then replacing $x$ by $2 x$ in (2.2), we obtain

$$
\left\|4 r f\left(\frac{2 x}{s}\right)-\gamma f(2 x)\right\|_{Y} \leq \varphi(2 x, 0,0)
$$

By (2.13) and (2.14), we get

$$
\begin{aligned}
\left\|\frac{f(2 x)}{4}-f(x)\right\|_{Y} & =\frac{1}{|4 \gamma|}\left\|2\left(2 r f\left(\frac{2 x}{s}\right)-2 \gamma f(x)\right)-\left(4 r f\left(\frac{2 x}{s}\right)-\gamma f(2 x)\right)\right\|_{Y} \\
& \leq \frac{1}{|4 \gamma|} \max \left\{|2|\left\|2 r f\left(\frac{2 x}{s}\right)-2 \gamma f(x)\right\|_{Y},\left\|4 r f\left(\frac{2 x}{s}\right)-\gamma f(2 x)\right\|_{Y}\right\} \\
& \leq \frac{1}{|4 \gamma|} \max \{\varphi(2 x, 0,0),|2| \varphi(x, x, 0)\} .
\end{aligned}
$$

The rest of the proof is similar to the proof of Theorem 2.1.

Corollary 2.6 Let $\theta$ be a positive real number and $q$ is a real number with $q>2$. Let $f$ : $X \rightarrow Y$ be an even mapping with $f(0)=0$ and satisfying (2.8). Then there exists a unique quadratic mapping $Q: X \rightarrow Y$ such that

$$
\|f(x)-Q(x)\|_{Y} \leq \frac{|4| 2|2| \theta\|x\|^{q}}{|4 \gamma|\left(|4|-|2|^{q}\right)}
$$

for all $x \in X$.

Proof The proof follows from Theorem 2.5 by taking $\varphi(x, y, z)=\theta\left(\|x\|^{q}+\|y\|^{q}+\|z\|^{q}\right)$ for all $x, y, z \in X$. Then we can choose $\alpha=|2|^{q-2}$ and we get the desired result.

Theorem 2.7 Let $X$ is a non-Archimedean normed space and that $Y$ be a complete nonArchimedean space. Let $\varphi: X^{3} \rightarrow[0, \infty)$ be a function such that there exists an $\alpha<1$ with

$$
\varphi\left(\frac{x}{2}, \frac{y}{2}, \frac{z}{2}\right) \leq \frac{\alpha}{|4|} \varphi(x, y, z)
$$


for all $x, y, z \in X$. Let $f: X \rightarrow Y$ be an even mapping with $f(0)=0$ and satisfying (2.2). Then there exists a unique quadratic mapping $Q: X \rightarrow Y$ such that

$$
\|f(x)-Q(x)\|_{Y} \leq \frac{\alpha \max \{\varphi(2 x, 0,0),|2| \varphi(x, x, 0)\}}{|4 \gamma|(1-\alpha)}
$$

for all $x \in X$.

Proof It follows from (2.15) that

$$
\begin{aligned}
\left\|f(x)-4 f\left(\frac{x}{2}\right)\right\|_{Y} & \leq \frac{1}{|\gamma|} \max \left\{\varphi(x, 0,0),|2| \varphi\left(\frac{x}{2}, \frac{x}{2}, 0\right)\right\} \\
& \leq \frac{\alpha}{|4 \gamma|} \max \{\varphi(2 x, 0,0),|2| \varphi(x, x, 0)\} .
\end{aligned}
$$

The rest of the proof is similar to the proof of Theorems 2.1 and 2.5.

Corollary 2.8 Let $\theta$ be a positive real number and $q$ is a real number with $0<q<2$. Let $f: X \rightarrow Y$ be an even mapping with $f(0)=0$ and satisfying (2.8). Then there exists a unique quadratic mapping $Q: X \rightarrow Y$ such that

$$
\|f(x)-Q(x)\|_{Y} \leq \frac{|4| 2|2| \theta\|x\|^{q}}{|4 \gamma|\left(|2|^{q}-|4|\right)}
$$

for all $x \in X$.

Proof The proof follows from Theorem 2.7 by taking $\varphi(x, y, z)=\theta\left(\|x\|^{q}+\|y\|^{q}+\|z\|^{q}\right)$ for all $x, y, z \in X$. Then we can choose $\alpha=|2|^{2-q}$ and we get the desired result.

Let $f: X \rightarrow Y$ be a mapping satisfying $f(0)=0$ and (1.1). Let $f_{e}(x):=\frac{f(x)+f(-x)}{2}$ and $f_{o}(x)=$ $\frac{f(x)-f(-x)}{2}$. Then $f_{e}$ is an even mapping satisfying (1.1) and $f_{o}$ is an odd mapping satisfying (1.1) such that $f(x)=f_{e}(x)+f_{o}(x)$.

On the other hand

$$
\left\|D_{f_{o}}(x, y, z)\right\| \leq \frac{\max \left\{D_{f}(x, y, z), D_{f}(-x,-y,-z)\right\}}{|2|} \leq \frac{\max \{\varphi(x, y, z), \varphi(-x,-y,-z)\}}{|2|}
$$

and

$$
\left\|D_{f_{e}}(x, y, z)\right\| \leq \frac{\max \left\{D_{f}(x, y, z), D_{f}(-x,-y,-z)\right\}}{|2|} \leq \frac{\max \{\varphi(x, y, z), \varphi(-x,-y,-z)\}}{|2|}
$$

for all $x, y, z \in X$, where $D_{f}(x, y, z)$ is the difference operator of the functional equation (1.1). So we obtain the following theorem.

Theorem 2.9 Let $X$ is a non-Archimedean normed space and that $Y$ be a complete nonArchimedean space. Let $\varphi: X^{3} \rightarrow[0, \infty)$ be a function such that there exists an $\alpha<1$ with

$$
\varphi(2 x, 2 y, 2 z) \leq|4| \alpha \varphi(x, y, z)
$$


for all $x, y, z \in X$. Let $f: X \rightarrow Y$ be a mapping with $f(0)=0$ and satisfying (2.2). Then there exist a unique additive mapping $A: X \rightarrow Y$ and a unique quadratic mapping $Q: X \rightarrow Y$ such that

$$
\begin{aligned}
&\|f(x)-A(x)-Q(x)\|_{Y} \\
& \leq \max \left\{\left\|\frac{f(x)-f(-x)}{2}-A(x)\right\|_{Y},\left\|\frac{f(x)+f(-x)}{2}-Q(x)\right\|_{Y}\right\} \\
& \leq \max \left\{\frac{\max \{\max \{\varphi(2 x, 0,0), \varphi(-2 x, 0,0)\}, \max \{\varphi(x, x, 0), \varphi(-x,-x, 0)\}\}}{|4 \gamma|(1-\alpha)},\right. \\
&\left.\frac{\max \{\max \{\varphi(2 x, 0,0), \varphi(-2 x, 0,0)\},|2| \max \{\varphi(x, x, 0), \varphi(-x,-x, 0)\}\}}{|8 \gamma|(1-\alpha)}\right\}
\end{aligned}
$$

for all $x \in X$.

Theorem 2.10 Let $X$ is a non-Archimedean normed space and that $Y$ be a complete nonArchimedean space. Let $\varphi: X^{3} \rightarrow[0, \infty)$ be a function such that there exists an $\alpha<1$ with

$$
\varphi\left(\frac{x}{2}, \frac{y}{2}, \frac{z}{2}\right) \leq \frac{\alpha \varphi(x, y, z)}{|2|}
$$

for all $x, y, z \in X$. Let $f: X \rightarrow Y$ be a mapping with $f(0)=0$ and satisfying (2.2). Then there exist a unique additive mapping $A: X \rightarrow Y$ and a unique quadratic mapping $Q: X \rightarrow Y$ such that

$$
\begin{aligned}
& \|f(x)-A(x)-Q(x)\|_{Y} \\
& \leq \alpha \max \left\{\frac{\max \{\max \{\varphi(2 x, 0,0), \varphi(-2 x, 0,0)\}, \max \{\varphi(x, x, 0), \varphi(-x,-x, 0)\}\}}{|4 \gamma|(1-\alpha)},\right. \\
& \left.\quad \frac{\max \{\max \{\varphi(2 x, 0,0), \varphi(-2 x, 0,0)\},|2| \max \{\varphi(x, x, 0), \varphi(-x,-x, 0)\}\}}{|8 \gamma|(1-\alpha)}\right\}
\end{aligned}
$$

for all $x \in X$.

\section{Stability of functional equation (1.1): a direct method}

In this section, using direct method, we prove the generalized Hyers-Ulam stability of the additive-quadratic functional equation (1.1) in non-Archimedean space.

Theorem 3.1 Let $G$ be a vector space and that $X$ is a non-Archimedean Banach space. Assume that $\varphi: G^{3} \rightarrow[0,+\infty)$ be a function such that

$$
\lim _{n \rightarrow \infty}|2|^{n} \varphi\left(\frac{x}{2^{n}}, \frac{y}{2^{n}}, \frac{z}{2^{n}}\right)=0
$$

for all $x, y, z \in G$. Suppose that, for any $x \in G$, the limit

$$
\Omega(x)=\lim _{n \rightarrow \infty} \max \left\{|2|^{k} \max \left\{\varphi\left(\frac{x}{2^{k}}, 0,0\right), \varphi\left(\frac{x}{2^{k+1}}, \frac{x}{2^{k+1}}, 0\right)\right\} ; 0 \leq k<n\right\}
$$


exists and $f: G \rightarrow X$ be an odd mapping satisfying

$$
\begin{aligned}
& \| r f\left(\frac{x+y+z}{s}\right)+r f\left(\frac{x-y+z}{s}\right)+r f\left(\frac{x+y-z}{s}\right) \\
& \quad+r f\left(\frac{-x+y+z}{s}\right)-\gamma f(x)-\gamma f(y)-\gamma f(z) \|_{X} \leq \varphi(x, y, z) .
\end{aligned}
$$

Then the limit

$$
A(x):=\lim _{n \rightarrow \infty} 2^{n} f\left(\frac{x}{2^{n}}\right)
$$

exists for all $x \in G$ and defines an additive mapping $A: G \rightarrow X$ such that

$$
\|f(x)-A(x)\| \leq \frac{1}{|\gamma|} \Omega(x) .
$$

Moreover, if

$$
\lim _{j \rightarrow \infty} \lim _{n \rightarrow \infty} \max \left\{|2|^{k} \max \left\{\varphi\left(\frac{x}{2^{k}}, 0,0\right), \varphi\left(\frac{x}{2^{k+1}}, \frac{x}{2^{k+1}}, 0\right)\right\} ; j \leq k<n+j\right\}=0
$$

then $A$ is the unique additive mapping satisfying (3.4).

Proof By (2.10), we know

$$
\left\|f(x)-2 f\left(\frac{x}{2}\right)\right\|_{X} \leq \frac{1}{|\gamma|} \max \left\{\varphi(x, 0,0), \varphi\left(\frac{x}{2}, \frac{x}{2}, 0\right)\right\}
$$

for all $x \in G$. Replacing $x$ by $\frac{x}{2^{n}}$ in (3.5), we obtain

$$
\begin{aligned}
& \left\|2^{n} f\left(\frac{x}{2^{n}}\right)-2^{n+1} f\left(\frac{x}{2^{n+1}}\right)\right\|_{X} \\
& \quad \leq \frac{|2|^{n}}{|\gamma|} \max \left\{\varphi\left(\frac{x}{2^{n}}, 0,0\right), \varphi\left(\frac{x}{2^{n+1}}, \frac{x}{2^{n+1}}, 0\right)\right\} .
\end{aligned}
$$

Thus, it follows from (3.1) and (3.6) that the sequence $\left\{2^{n} f\left(\frac{x}{2^{n}}\right)\right\}_{n \geq 1}$ is a Cauchy sequence. Since $X$ is complete, it follows that $\left\{2^{n} f\left(\frac{x}{2^{n}}\right)\right\}_{n \geq 1}$ is convergent. Set

$$
A(x):=\lim _{n \rightarrow \infty} 2^{n} f\left(\frac{x}{2^{n}}\right) .
$$

By induction on $n$, one can show that

$$
\begin{aligned}
& \left\|2^{n} f\left(\frac{x}{2^{n}}\right)-f(x)\right\|_{X} \\
& \quad \leq \frac{1}{|\gamma|} \max \left\{|2|^{k} \max \left\{\varphi\left(\frac{x}{2^{k}}, 0,0\right), \varphi\left(\frac{x}{2^{k+1}}, \frac{x}{2^{k+1}}, 0\right)\right\} ; 0 \leq k<n\right\}
\end{aligned}
$$


for all $n \geq 1$ and $x \in$ G. By taking $n \rightarrow \infty$ in (3.7) and using (3.2), one obtains (3.4). By (3.1) and (3.3), we get

$$
\begin{aligned}
\| r A & \left(\frac{x+y+z}{s}\right)+r A\left(\frac{x-y+z}{s}\right)+r A\left(\frac{x+y-z}{s}\right) \\
& +r A\left(\frac{-x+y+z}{s}\right)-\gamma A(x)-\gamma A(y)-\gamma A(z) \|_{X} \\
= & \lim _{n \rightarrow \infty}|2|^{n} \| r f\left(\frac{x+y+z}{2^{n} s}\right)+r f\left(\frac{x-y+z}{2^{n} s}\right)+r f\left(\frac{x+y-z}{2^{n} s}\right) \\
& +r f\left(\frac{-x+y+z}{2^{n} s}\right)-\gamma f\left(\frac{x}{2^{n}}\right)-\gamma f\left(\frac{y}{2^{n}}\right)-\gamma f\left(\frac{z}{2^{n}}\right) \|_{X} \\
\leq & \lim _{n \rightarrow \infty}|2|^{n} \varphi\left(\frac{x}{2^{n}}, \frac{y}{2^{n}}, \frac{z}{2^{n}}\right) \\
= & 0
\end{aligned}
$$

for all $x, y, z \in X$. Therefore, the mapping $A: G \rightarrow X$ satisfies (1.1).

To prove the uniqueness property of $A$, let $L$ be another mapping satisfying (3.4). Then we have

$$
\begin{aligned}
& \|A(x)-L(x)\|_{X} \\
& =\lim _{n \rightarrow \infty}|2|^{n}\left\|A\left(\frac{x}{2^{n}}\right)-L\left(\frac{x}{2^{n}}\right)\right\|_{X} \\
& \leq \lim _{k \rightarrow \infty}|2|^{n} \max \left\{\left\|A\left(\frac{x}{2^{n}}\right)-f\left(\frac{x}{2^{n}}\right)\right\|_{X},\left\|f\left(\frac{x}{2^{n}}\right)-L\left(\frac{x}{2^{n}}\right)\right\|_{X}\right\} \\
& \quad \leq \lim _{j \rightarrow \infty} \lim _{n \rightarrow \infty} \max \left\{|2|^{k} \max \left\{\varphi\left(\frac{x}{2^{k}}, 0,0\right), \varphi\left(\frac{x}{2^{k+1}}, \frac{x}{2^{k+1}}, 0\right)\right\} ; j \leq k<n+j\right\} \\
& =0
\end{aligned}
$$

for all $x \in G$. Therefore, $A=L$. This completes the proof.

Corollary 3.2 Let $\xi:[0, \infty) \rightarrow[0, \infty)$ be a function satisfying

$$
\xi\left(|2|^{-1} t\right) \leq \xi\left(|2|^{-1}\right) \xi(t), \quad \xi\left(|2|^{-1}\right)<|2|^{-1}
$$

for all $t \geq 0$. Assume that $\kappa>0$ and $f: G \rightarrow X$ be a mapping with $f(0)=0$ such that

$$
\begin{aligned}
& \| r f\left(\frac{x+y+z}{s}\right)+r f\left(\frac{x-y+z}{s}\right)+r f\left(\frac{x+y-z}{s}\right) \\
& \quad+r f\left(\frac{-x+y+z}{s}\right)-\gamma f(x)-\gamma f(y)-\gamma f(z) \|_{X} \leq \kappa(\xi(\|x\|)+\xi(\|y\|)+\xi(\|z\|))
\end{aligned}
$$

for all $x, y, z \in G$. Then there exists a unique additive mapping $A: G \rightarrow X$ such that

$$
\|f(x)-A(x)\|_{X} \leq \frac{1}{|\gamma|} \max \left\{\kappa \zeta(\|x\|), \frac{2}{|2|} \kappa \zeta(\|x\|)\right\} .
$$


Proof Defining $\varphi: G^{3} \rightarrow[0, \infty)$ by $\varphi(x, y, z):=\kappa(\xi(\|x\|)+\xi(\|y\|)+\xi(\|z\|))$, then we have

$$
\lim _{n \rightarrow \infty}|2|^{n} \varphi\left(\frac{x}{2^{n}}, \frac{y}{2^{n}}, \frac{z}{2^{n}}\right) \leq \lim _{n \rightarrow \infty}\left(|2| \xi\left(|2|^{-1}\right)\right)^{n} \varphi(x, y, z)=0
$$

for all $x, y, z \in G$. The last equality comes form the fact that $|2| \xi\left(|2|^{-1}\right)<1$. On the other hand, it follows that

$$
\begin{aligned}
\Omega(x) & =\lim _{n \rightarrow \infty} \max \left\{|2|^{k} \max \left\{\varphi\left(\frac{x}{2^{k}}, 0,0\right), \varphi\left(\frac{x}{2^{k+1}}, \frac{x}{2^{k+1}}, 0\right)\right\} ; 0 \leq k<n\right\} \\
& \leq \max \left\{\varphi(x, 0,0), \varphi\left(\frac{x}{2}, \frac{x}{2}, 0\right)\right\} \\
& =\max \left\{\kappa \zeta(\|x\|), \frac{2}{|2|} \kappa \zeta(\|x\|)\right\}
\end{aligned}
$$

exists for all $x \in G$. Also, we have

$$
\begin{aligned}
& \lim _{j \rightarrow \infty} \lim _{n \rightarrow \infty} \max \left\{|2|^{k} \max \left\{\varphi\left(\frac{x}{2^{k}}, 0,0\right), \varphi\left(\frac{x}{2^{k+1}}, \frac{x}{2^{k+1}}, 0\right)\right\} ; j \leq k<n+j\right\} \\
& =\lim _{j \rightarrow \infty}|2|^{j} \max \left\{\varphi\left(\frac{x}{2^{j}}, 0,0\right), \varphi\left(\frac{x}{2^{j+1}}, \frac{x}{2^{j+1}}, 0\right)\right\} \\
& =0 .
\end{aligned}
$$

Thus, applying Theorem 3.1, we have the conclusion. This completes the proof.

Theorem 3.3 Let $G$ be a vector space and that $X$ is a non-Archimedean Banach space. Assume that $\varphi: G^{3} \rightarrow[0,+\infty)$ be a function such that

$$
\lim _{n \rightarrow \infty} \frac{\varphi\left(2^{n} x, 2^{n} y, 2^{n} z\right)}{|2|^{n}}=0
$$

for all $x, y, z \in G$. Suppose that, for any $x \in G$, the limit

$$
\Omega(x)=\lim _{n \rightarrow \infty} \max \left\{\frac{\max \left\{\varphi\left(2^{k+1} x, 0,0\right), \varphi\left(2^{k} x, 2^{k} x, 0\right)\right\}}{|2|^{k}} ; 0 \leq k<n\right\}
$$

exists and $: G \rightarrow X$ be an odd mapping satisfying (3.3). Then the limit $A(x):=\lim _{n \rightarrow \infty} \frac{f\left(2^{n} x\right)}{2^{n}}$ exists for all $x \in G$ and

$$
\|f(x)-A(x)\|_{X} \leq \frac{1}{|2 \gamma|} \Omega(x)
$$

for all $x \in G$. Moreover, if

$$
\lim _{j \rightarrow \infty} \lim _{n \rightarrow \infty} \max \left\{\frac{\max \left\{\varphi\left(2^{k+1} x, 0,0\right), \varphi\left(2^{k} x, 2^{k} x, 0\right)\right\}}{|2|^{k}} ; j \leq k<n+j\right\}=0,
$$


Proof By (2.6), we get

$$
\left\|\frac{f(2 x)}{2}-f(x)\right\|_{X} \leq \frac{\max \{\varphi(2 x, 0,0), \varphi(x, x, 0)\}}{|2 \gamma|}
$$

for all $x \in G$. Replacing $x$ by $2^{n} x$ in (3.12), we obtain

$$
\left\|\frac{f\left(2^{n+1} x\right)}{2^{n+1}}-\frac{f\left(2^{n} x\right)}{2^{n}}\right\|_{X} \leq \frac{\max \left\{\varphi\left(2^{n+1} x, 0,0\right), \varphi\left(2^{n} x, 2^{n} x, 0\right)\right\}}{|2 \gamma \| 2|^{n}} .
$$

Thus, it follows from (3.9) and (3.13) that the sequence $\left\{\frac{f\left(2^{n} x\right)}{2^{n}}\right\}_{n \geq 1}$ is convergent. Set

$$
A(x):=\lim _{n \rightarrow \infty} \frac{f\left(2^{n} x\right)}{2^{n}}
$$

On the other hand, it follows from (3.13) that

$$
\begin{aligned}
& \left\|\frac{f\left(2^{p} x\right)}{2^{q}}-\frac{f\left(2^{q} x\right)}{2^{q}}\right\|_{X} \\
& \quad=\left\|\sum_{k=p}^{q-1} \frac{f\left(2^{k+1} x\right)}{2^{k+1}}-\frac{f\left(2^{k} x\right)}{2^{k}}\right\|_{X} \\
& \quad \leq \max \left\{\left\|\frac{f\left(2^{k+1} x\right)}{2^{k+1}}-\frac{f\left(2^{k} x\right)}{2^{k}}\right\|_{X} ; p \leq k<q-1\right\} \\
& \quad \leq \frac{1}{|2 \gamma|} \max \left\{\frac{\max \left\{\varphi\left(2^{k+1} x, 0,0\right), \varphi\left(2^{k} x, 2^{k} x, 0\right)\right\}}{|2|^{k}} ; p \leq k<q\right\}
\end{aligned}
$$

for all $x \in G$ and $p, q \geq 0$ with $q>p \geq 0$. Letting $p=0$, taking $q \rightarrow \infty$ in the last inequality and using (3.10), we obtain (3.11).

The rest of the proof is similar to the proof of Theorem 3.1. This completes the proof.

Theorem 3.4 Let $G$ be a vector space and that $X$ is a non-Archimedean Banach space. Assume that $\varphi: G^{3} \rightarrow[0,+\infty)$ be a function such that

$$
\lim _{n \rightarrow \infty}|4|^{n} \varphi\left(\frac{x}{2^{n}}, \frac{y}{2^{n}}, \frac{z}{2^{n}}\right)=0
$$

for all $x, y, z \in G$. Suppose that, for any $x \in G$, the limit

$$
\Theta(x)=\lim _{n \rightarrow \infty} \max \left\{|4|^{k} \max \left\{\varphi\left(\frac{x}{2^{k}}, 0,0\right),|2| \varphi\left(\frac{x}{2^{k+1}}, \frac{x}{2^{k+1}}, 0\right)\right\} ; 0 \leq k<n\right\}
$$

exists and $f: G \rightarrow X$ be an even mapping with $f(0)=0$ and satisfying (3.3). Then the limit $Q(x):=\lim _{n \rightarrow \infty} 4^{n} f\left(\frac{x}{2^{n}}\right)$ exists for all $x \in G$ and defines a quadratic mapping $Q: G \rightarrow X$ such that

$$
\|f(x)-Q(x)\|_{X} \leq \frac{1}{|\gamma|} \Theta(x) .
$$


Moreover, if

$$
\lim _{j \rightarrow \infty} \lim _{n \rightarrow \infty} \max \left\{|4|^{k} \max \left\{\varphi\left(\frac{x}{2^{k}}, 0,0\right),|2| \varphi\left(\frac{x}{2^{k+1}}, \frac{x}{2^{k+1}}, 0\right)\right\} ; j \leq k<n+j\right\}=0
$$

then $Q$ is the unique additive mapping satisfying (3.16).

Proof It follows from (2.15) that

$$
\left\|f(x)-4 f\left(\frac{x}{2}\right)\right\|_{X} \leq \frac{1}{|\gamma|} \max \left\{\varphi(x, 0,0),|2| \varphi\left(\frac{x}{2}, \frac{x}{2}, 0\right)\right\} .
$$

Replacing $x$ by $\frac{x}{2^{n}}$ in (3.18), we have

$$
\left\|4^{n} f\left(\frac{x}{2^{n}}\right)-4^{n+1} f\left(\frac{x}{2^{n+1}}\right)\right\|_{X} \leq \frac{|4|^{n}}{|\gamma|} \max \left\{\varphi\left(\frac{x}{2^{n}}, 0,0\right),|2| \varphi\left(\frac{x}{2^{n+1}}, \frac{x}{2^{n+1}}, 0\right)\right\} .
$$

It follows from (3.14) and (3.18) that the sequence $\left\{4^{n} f\left(\frac{x}{2^{n}}\right)\right\}_{n \geq 1}$ is Cauchy sequence. The rest of the proof is similar to the proof of Theorem 3.1.

Similarly, we can obtain the followings. We will omit the proof.

Theorem 3.5 Let $G$ be a vector space and that $X$ is a non-Archimedean Banach space. Assume that $\varphi: G^{3} \rightarrow[0,+\infty)$ be a function such that

$$
\lim _{n \rightarrow \infty} \frac{\varphi\left(2^{n} x, 2^{n} y, 2^{n} z\right)}{|4|^{n}}=0
$$

for all $x, y, z \in G$. Suppose that, for any $x \in G$, the limit

$$
\Theta(x)=\lim _{n \rightarrow \infty} \max \left\{\frac{\max \left\{\varphi\left(2^{k+1} x, 0,0\right), \varphi\left(2^{k} x, 2^{k} x, 0\right)\right\}}{|4|^{k}} ; 0 \leq k<n\right\}
$$

exists and $f: G \rightarrow X$ be an even mapping with $f(0)=0$ and satisfying (3.3). Then the limit $Q(x):=\lim _{n \rightarrow \infty} \frac{f\left(2^{n} x\right)}{4^{n}}$ exists for all $x \in G$ and

$$
\|f(x)-Q(x)\|_{X} \leq \frac{1}{|4 \gamma|} \Theta(x)
$$

for all $x \in G$. Moreover, if

$$
\lim _{j \rightarrow \infty} \lim _{n \rightarrow \infty} \max \left\{\frac{\max \left\{\varphi\left(2^{k+1} x, 0,0\right), \varphi\left(2^{k} x, 2^{k} x, 0\right)\right\}}{|4|^{k}} ; j \leq k<n+j\right\}=0,
$$

then $Q$ is the unique mapping satisfying (3.21).

Let $f: X \rightarrow Y$ be a mapping satisfying $f(0)=0$ and (1.1). Let $f_{e}(x):=\frac{f(x)+f(-x)}{2}$ and $f_{o}(x)=$ $\frac{f(x)-f(-x)}{2}$. Then $f_{e}$ is an even mapping satisfying (1.1) and $f_{o}$ is an odd mapping satisfying (1.1) such that $f(x)=f_{e}(x)+f_{o}(x)$. On the other hand,

$$
\left\|D_{f_{o}}(x, y, z)\right\| \leq \frac{\max \{\varphi(x, y, z), \varphi(-x,-y,-z)\}}{|2|}
$$


and

$$
\left\|D_{f_{e}}(x, y, z)\right\| \leq \frac{\max \{\varphi(x, y, z), \varphi(-x,-y,-z)\}}{|2|}
$$

for all $x, y, z \in X$, where $D_{f}(x, y, z)$ is the difference operator of the functional equation (1.1). So we obtain the following theorem.

Theorem 3.6 Let $G$ be a vector space and that $X$ is a non-Archimedean Banach space. Assume that $\varphi: G^{3} \rightarrow[0,+\infty)$ be a function such that

$$
\lim _{n \rightarrow \infty} \frac{\varphi\left(2^{n} x, 2^{n} y, 2^{n} z\right)}{|4|^{n}}=0
$$

for all $x, y, z \in G$. Suppose that the limits

$$
\begin{aligned}
\Omega^{*}(x)= & \lim _{n \rightarrow \infty} \max _{0 \leq k<n}\left\{\operatorname { m a x } \left\{\max \left\{\varphi\left(2^{k+1} x, 0,0\right), \varphi\left(-2^{k+1} x, 0,0\right)\right\},\right.\right. \\
& \left.\left.\max \left\{\varphi\left(2^{k} x, 2^{k} x, 0\right), \varphi\left(-2^{k} x,-2^{k} x, 0\right)\right\}\right\} /|2|^{k+1}\right\}
\end{aligned}
$$

and

$$
\begin{aligned}
\Theta^{*}(x)= & \lim _{n \rightarrow \infty} \max _{0 \leq k<n}\left\{\operatorname { m a x } \left\{\max \left\{\varphi\left(2^{k+1} x, 0,0\right), \varphi\left(-2^{k+1} x, 0,0\right)\right\},\right.\right. \\
& \left.\left.\max \left\{\varphi\left(2^{k} x, 2^{k} x, 0\right), \varphi\left(-2^{k} x,-2^{k} x, 0\right)\right\}\right\} /\left(|2||4|^{k}\right)\right\}
\end{aligned}
$$

exist for all $x \in G$ and $f: G \rightarrow X$ be a mapping with $f(0)=0$ and satisfying (3.3). Then there exist an additive mapping $A: G \rightarrow X$ and a quadratic mapping $Q: G \rightarrow X$ such that

$$
\begin{aligned}
& \|f(x)-A(x)-Q(x)\|_{X} \\
& \quad \leq \max \left\{\left\|\frac{f(x)+f(-x)}{2}-Q(x)\right\|_{X},\left\|\frac{f(x)-f(-x)}{2}-A(x)\right\|_{X}\right\} \\
& \quad \leq \max \left\{\frac{1}{|2 \gamma|} \Omega^{*}(x), \frac{1}{|4 \gamma|} \Theta^{*}(x)\right\}
\end{aligned}
$$

for all $x \in G$. Moreover, if

$$
\begin{gathered}
\lim _{j \rightarrow \infty} \lim _{n \rightarrow \infty} \max _{j \leq k<n+j}\left\{\operatorname { m a x } \left\{\max \left\{\varphi\left(2^{k+1} x, 0,0\right), \varphi\left(-2^{k+1} x, 0,0\right)\right\},\right.\right. \\
\left.\left.\max \left\{\varphi\left(2^{k} x, 2^{k} x, 0\right), \varphi\left(-2^{k} x,-2^{k} x, 0\right)\right\}\right\} /|2|^{k+1}\right\}=0
\end{gathered}
$$

and

$$
\begin{gathered}
\lim _{j \rightarrow \infty} \lim _{n \rightarrow \infty} \max _{j \leq k<n+j}\left\{\operatorname { m a x } \left\{\max \left\{\varphi\left(2^{k+1} x, 0,0\right), \varphi\left(-2^{k+1} x, 0,0\right)\right\},\right.\right. \\
\left.\left.\max \left\{\varphi\left(2^{k} x, 2^{k} x, 0\right), \varphi\left(-2^{k} x,-2^{k} x, 0\right)\right\}\right\} /\left(|2||4|^{k}\right)\right\}=0
\end{gathered}
$$

then $A, Q$ are the unique mappings satisfying (3.22). 
Theorem 3.7 Let $G$ be a vector space and that $X$ is a non-Archimedean Banach space. Assume that $\varphi: G^{3} \rightarrow[0,+\infty)$ be a function such that

$$
\lim _{n \rightarrow \infty}|2|^{n} \varphi\left(\frac{x}{2^{n}}, \frac{y}{2^{n}}, \frac{z}{2^{n}}\right)=0
$$

for all $x, y, z \in G$. Suppose that the limits

$$
\begin{aligned}
\Omega^{* *}(x)= & \frac{1}{|2|} \lim _{n \rightarrow \infty} \max _{0 \leq k<n}\left\{| 2 | ^ { k } \operatorname { m a x } \left\{\max \left\{\varphi\left(\frac{x}{2^{k}}, 0,0\right), \varphi\left(\frac{-x}{2^{k}}, 0,0\right)\right\},\right.\right. \\
& \left.\left.\max \left\{\varphi\left(\frac{x}{2^{k+1}}, \frac{x}{2^{k+1}}, 0\right), \varphi\left(\frac{-x}{2^{k+1}}, \frac{-x}{2^{k+1}}, 0\right)\right\}\right\}\right\}
\end{aligned}
$$

and

$$
\begin{aligned}
\Theta^{* *}(x)= & \frac{1}{|2|} \lim _{n \rightarrow \infty} \max _{0 \leq k<n}\left\{| 4 | ^ { k } \operatorname { m a x } \left\{\max \left\{\varphi\left(\frac{x}{2^{k}}, 0,0\right), \varphi\left(\frac{-x}{2^{k}}, 0,0\right)\right\},\right.\right. \\
& \left.\left.|2| \max \left\{\varphi\left(\frac{x}{2^{k+1}}, \frac{x}{2^{k+1}}, 0\right), \varphi\left(\frac{-x}{2^{k+1}}, \frac{-x}{2^{k+1}}, 0\right)\right\}\right\}\right\}
\end{aligned}
$$

exist for all $x \in G$ and $f: G \rightarrow X$ be a mapping with $f(0)=0$ and satisfying (3.3). Then there exist an additive mapping $A: G \rightarrow X$ and a quadratic mapping $Q: G \rightarrow X$ such that

$$
\|f(x)-A(x)-Q(x)\|_{X} \leq \frac{\max \left\{\Omega^{* *}(x), \Theta^{* * *}(x)\right\}}{|\gamma|}
$$

for all $x \in G$. Moreover, if

$$
\begin{gathered}
\lim _{j \rightarrow \infty} \lim _{n \rightarrow \infty} \max _{j \leq k<n+j}\left\{| 2 | ^ { k } \operatorname { m a x } \left\{\max \left\{\varphi\left(\frac{x}{2^{k}}, 0,0\right), \varphi\left(\frac{-x}{2^{k}}, 0,0\right)\right\},\right.\right. \\
\left.\left.\max \left\{\varphi\left(\frac{x}{2^{k+1}}, \frac{x}{2^{k+1}}, 0\right), \varphi\left(\frac{-x}{2^{k+1}}, \frac{-x}{2^{k+1}}, 0\right)\right\}\right\}\right\}=0
\end{gathered}
$$

and

$$
\begin{gathered}
\lim _{j \rightarrow \infty} \lim _{n \rightarrow \infty} \max _{j \leq k<n+j}\left\{| 4 | ^ { k } \operatorname { m a x } \left\{\max \left\{\varphi\left(\frac{x}{2^{k}}, 0,0\right), \varphi\left(\frac{-x}{2^{k}}, 0,0\right)\right\},\right.\right. \\
\left.\left.|2| \max \left\{\varphi\left(\frac{x}{2^{k+1}}, \frac{x}{2^{k+1}}, 0\right), \varphi\left(\frac{-x}{2^{k+1}}, \frac{-x}{2^{k+1}}, 0\right)\right\}\right\}\right\}=0
\end{gathered}
$$

then $A, Q$ are the unique mappings satisfying (3.23).

\section{Conclusion}

We linked here two different disciplines, namely, the non-Archimedean normed spaces and functional equations. We established the generalized Hyers-Ulam stability of the functional equation (1.1) in non-Archimedean normed spaces. 


\section{Authors' contributions}

All authors conceived of the study, participated in its design and coordination, drafted the manuscript, participated in the sequence alignment, and read and approved the final manuscript.

\section{Author details}

1 Department of Mathematics, Hanyang University, Seoul, South Korea. ${ }^{2}$ Department of Mathematics, College of Sciences, Yasouj University, Yasouj, 75914-353, Iran. ${ }^{3}$ Department of Mathematics, National Technical University of Athens, Zografou, Campus, Athens, 15780, Greece.

Received: 29 September 2011 Accepted: 27 July 2012 Published: 6 August 2012

\section{References}

1. Aoki, T: On the stability of the linear transformation in Banach spaces. J. Math. Soc. Jpn. 2, 64-66 (1950)

2. Arriola, LM, Beyer, WA: Stability of the Cauchy functional equation over $p$-adic fields. Real Anal. Exch. 31, 125-132 (2005/06)

3. Azadi Kenary, H: Stability of a pexiderial functional equation in random normed spaces. Rend. Circ. Mat. Palermo (2011). doi:10.1007/s12215-011-0027-5

4. Azadi Kenary, H: Non-Archimedean stability of Cauchy-Jensen type functional equation. Int. J. Nonlinear Anal. Appl. 2(2), 93-103 (2011)

5. Azadi Kenary, H: Approximate additive functional equations in closed convex cone. J. Math. Ext. 5(2), 51-65 (2011)

6. Azadi Kenary, $\mathrm{H}$ : On the stability of a cubic functional equation in random normed spaces. J. Math. Ext. 4(1), 105-113 (2009)

7. Azadi Kenary, H, Rezaei, H, Talebzadeh, S, Lee, SJ: Stabilities of cubic mappings in various normed spaces: direct and fixed point methods. J. Appl. Math. 2012, Article ID 546819 (2012). doi:10.1155/2012/546819

8. Azadi Kenary, H, Rezaei, H, Ebadian, A, Zohdi, AR: Hyers-Ulam-Rassias RNS approximation of Euler-Lagrange-type additive mappings. Math. Probl. Eng. 2012, Article ID 672531 (2012). doi:10.1155/2012/672531

9. Azadi Kenary, H, Shafaat, K, Shafiee, M, Takbiri, G: Hyers-Ulam-Rassias stability of the Apollonius type quadratic mapping in RN-spaces. J. Nonlinear Sci. Appl. 4(1), 82-91 (2011)

10. Cădariu, L, Radu, V: Fixed points and the stability of Jensen's functional equation. J. Inequal. Pure Appl. Math. 4(1), Article ID 4 (2003)

11. Cholewa, PW: Remarks on the stability of functional equations. Aequ. Math. 27, 76-86 (1984)

12. Chung, J, Sahoo, PK: On the general solution of a quartic functional equation. Bull. Korean Math. Soc. 40, 565-576 (2003)

13. Czerwik, S: Functional Equations and Inequalities in Several Variables. World Scientific, River Edge (2002)

14. Cădariu, L, Radu, V: On the stability of the Cauchy functional equation: a fixed point approach. Grazer Math. Ber. 346, 43-52 (2004)

15. Cădariu, L, Radu, V: Fixed point methods for the generalized stability of functional equations in a single variable. Fixed Point Theory Appl. 2008, Article ID 749392 (2008)

16. Deses, D: On the representation of non-Archimedean objects. Topol. Appl. 153, 774-785 (2005)

17. Diaz, J, Margolis, B: A fixed point theorem of the alternative for contractions on a generalized complete metric space. Bull. Am. Math. Soc. 74, 305-309 (1968)

18. Eshaghi-Gordji, M, Abbaszadeh, S, Park, C: On the stability of a generalized quadratic and quartic type functional equation in quasi-Banach spaces. J. Inequal. Appl. 2009, Article ID 153084 (2009)

19. Eshaghi-Gordji, M, Kaboli-Gharetapeh, S, Park, C, Zolfaghri, S: Stability of an additive-cubic-quartic functional equation. Adv. Differ. Equ. 2009, Article ID 395693 (2009)

20. Fechner, W: Stability of a functional inequality associated with the Jordan-von Neumann functional equation. Aequ. Math. 71, 149-161 (2006)

21. Găvruta, P: A generalization of the Hyers-Ulam-Rassias stability of approximately additive mappings. J. Math. Anal. Appl. 184, 431-436 (1994)

22. Hensel, K: Ubereine news Begrundung der Theorie der algebraischen Zahlen. Jahresber. Dtsch. Math.-Ver. 6, 83-88 (1897)

23. Hyers, DH: On the stability of the linear functional equation. Proc. Natl. Acad. Sci. USA 27, $222-224$ (1941)

24. Hyers, DH, Isac, G, Rassias, TM: Stability of Functional Equations in Several Variables. Birkhäuser, Basel (1998)

25. Katsaras, AK, Beoyiannis, A: Tensor products of non-Archimedean weighted spaces of continuous functions. Georgian Math. J. 6, 33-44 (1999)

26. Khrennikov, A: Non-Archimedean Analysis: Quantum Paradoxes, Dynamical Systems and Biological Models. Mathematics and Its Applications, vol. 427. Kluwer Academic, Dordrecht (1997)

27. Kominek, Z: On a local stability of the Jensen functional equation. Demonstr. Math. 22, 499-507 (1989)

28. Lee, S, Im, S, Hwang, I: Quartic functional equations. J. Math. Anal. Appl. 307, 387-394 (2005)

29. Mohammadi, M, Cho, YJ, Park, C, Vetro, P, Saadati, R: Random stability of an additive-quadratic-quartic functional equation. J. Inequal. Appl. 2010, Article ID 754210 (2010)

30. Mihet, D, Radu, V: On the stability of the additive Cauchy functional equation in random normed spaces. J. Math. Anal. Appl. 343, 567-572 (2008)

31. Mursaleen, M, Mohiuddine, SA: On stability of a cubic functional equation in intuitionistic fuzzy normed spaces. Chaos Solitons Fractals 42, 2997-3005 (2009)

32. Najati, A, Park, C: The pexiderized Apollonius-Jensen type additive mapping and isomorphisms between $C^{*}$-algebras J. Differ. Equ. Appl. 14, 459-479 (2008)

33. Nyikos, PJ: On some non-Archimedean spaces of Alexandrof and Urysohn. Topol. Appl. 91, 1-23 (1999)

34. Park, C: Generalized Hyers-Ulam-Rassias stability of $n$-sesquilinear-quadratic mappings on Banach modules over $C^{*}$-algebras. J. Comput. Appl. Math. 180, 279-291 (2005)

35. Park, C: Fixed points and Hyers-Ulam-Rassias stability of Cauchy-Jensen functional equations in Banach algebras. Fixed Point Theory Appl. 2007, Article ID 50175 (2007) 
36. Park, C: Generalized Hyers-Ulam-Rassias stability of quadratic functional equations: a fixed point approach. Fixed Point Theory Appl. 2008, Article ID 493751 (2008)

37. Parnami, JC, Vasudeva, HL: On Jensen's functional equation. Aequ. Math. 43, 211-218 (1992)

38. Radu, V: The fixed point alternative and the stability of functional equations. Fixed Point Theory 4, 91-96 (2003)

39. Rassias, TM: On the stability of the linear mapping in Banach spaces. Proc. Am. Math. Soc. 72, $297-300$ (1978)

40. Rätz, J: On inequalities associated with the Jordan-von Neumann functional equation. Aequ. Math. 66, 191-200 (2003)

41. Saadati, R, Park, C: Non-Archimedean $\mathcal{L}$-fuzzy normed spaces and stability of functional equations. Comput. Math. Appl. 60, 2488-2496 (2010)

42. Saadati, R, Park, JH: On the intuitionistic fuzzy topological spaces. Chaos Solitons Fractals 27, 331-344 (2006)

43. Skof, F: Local properties and approximation of operators. Rend. Semin. Mat. Fis. Milano 53, 113-129 (1983)

44. Ulam, SM: Problems in Modern Mathematics. Science Editions. Wiley, New York (1964)

doi:10.1186/1029-242X-2012-174

Cite this article as: Park et al.: Hyers-Ulam-Rassias stability of the additive-quadratic mappings in non-Archimedean Banach spaces. Journal of Inequalities and Applications 2012 2012:174.

\section{Submit your manuscript to a SpringerOpen ${ }^{\ominus}$ journal and benefit from:}

- Convenient online submission

- Rigorous peer review

Immediate publication on acceptance

- Open access: articles freely available online

- High visibility within the field

- Retaining the copyright to your article 